\title{
State of the Art and Emerging Trends in Additive Manufacturing: From Multi-Material processes to 3D printed Electronics
}

\author{
Dirk Lehmhus ${ }^{1, *}$, Matthias Busse ${ }^{1}$, Axel von $\mathrm{Hehl}^{2}$, and Eric Jägle ${ }^{3}$ \\ ${ }^{1}$ Fraunhofer Institute for Manufacturing Technology and Advanced Materials (IFAM), , 28359 \\ Bremen, Germany \\ ${ }^{2}$ Leibniz-Institut für Werkstofforientierte Technologien (IWT), 28359 Bremen, Germany \\ ${ }^{3}$ Max-Planck-Institut für Eisenforschung GmbH, 40237 Düsseldorf, Germany
}

\begin{abstract}
Additive manufacturing is considered a disruptive technology that is expected to revolutionize production technology and affect value chains on a global scale. The scope of accessible materials ranges from polymers to metals and ceramics as well as composites. The keynote will provide an overview of available manufacturing processes for the various material groups and discuss the specific advantages of additive manufacturing - e.g. realization of complex geometries, part count and assembly effort reduction, art-to-part approach - in view of selected applications and production scenarios. Further to this, selected emerging trends in additive manufacturing will be presented and discussed, including fabrication of composites, hybrid structures, multi-material techniques and associated promises with respect to local tailoring of material properties, and the integration of sensors and/or electronic systems in AM parts.
\end{abstract}

\section{Introduction}

In recent years, Additive Manufacturing (AM) has developed from a prototyping technology into a group of established manufacturing processes. Wohlers, as the primary reference in this respect, reports a total AM industry size, by turnover, of 5.182 billion US$\$$ in $2015(+25.9 \%$ relative to the preceding year) via 6.063 billion US-\$ in $2016(+17.4 \%)$ to 7.336 billion US-\$ in 2017 (+21\%) [1]. Metal AM, which reflects industrial interest, has a more-than-average share in this development. The dynamics of this sub-market are illustrated by the number of metal AM systems sold in 2016 and 2017, i.e. 983 and 1768, respectively, a rise of nearly $80 \%$ in a single year [1].

AM generally excels due to qualities like almost limitless geometric flexibility, nonnecessity of tools and short lead times and is thus able, as Conner et al. have pointed out, to find its niche in almost any market segment defined by either high or low levels of customization, complexity and production volume, with classical mass production the only exception [2]. Furthermore, again based on flexibility and "art-to-part" (direct transfer of a digital design to the manufacturing system) approach, AM links up easily with the

* Corresponding author: dirk.lehmhus@ifam.fraunhofer.de 
"Industry 4.0" manufacturing paradigm, supporting concepts like Cloud-based (Additive) Manufacturing and Design (CBDM) [3]. The recent, rapid development of the AM industry has to a considerable degree been fuelled by the transport sector and its specific interest in lightweight design [4,5]. Besides, medical technology profits greatly by AM for customized, patient-specific tools, positioning devices, implants, prostheses and ortheses [6-9]. The present paper highlights selected aspects consider specifically relevant or interesting in describing of state of the art (section 2) and future trends (section 3).

\section{AM Processes and Materials: State of the Art}

\subsection{Processes}

AM is not a single process, but a group of processes which may differ significantly in terms of the approach they follow. The ASTM has ordered the chaos by suggestion a classification reflected in table 1 [10]. Common to these classes is the fact that component shape is neither generated by removing material (as e.g. in metal cutting, turning or milling), nor by replicating a negative of the final part (forging, casting). Instead, material is added where needed based on a digital model of the planned result. In this, most methods follow a layer-wise approach. Consequently, the original digital model needs to be sliced to extract the pattern to be produced in each layer.

As far as commercial processes and systems are concerned, current developments are very much focussed on large-scale commercialization, targeting e. g. increase of build rates. In Laser Beam Melting (LBM), for example, higher build rates are realized e.g. by using multiple lasers, or by shifting the creation of satisfactory surface qualities from primary to post processing: This way, coarser powders and thicker layers can be used. A resulting higher internal defect density is compensated for safety-critical parts by hot isostatic pressing (HIP).

The same aim motivates high throughput solutions like Wire + Arc Additive Manufacturing (WAAM) [11]. These differ from conventional AM semi-finished product machined afterwards to final (net) shape: High buy-to-fly ratios as often seen in the aerospace industry, justify this approach in view of cost and resource efficiency. This is achieved a the cost of part of the geometrical flexibility: Possible geometries are defined by the need to guarantee access for secondary milling operations. Internal cavities, for example, are thus excluded.

Beyond productivity, quality and reproducibility are major fields or research and development. Thus an evolutionary trend in AM is the introduction of approaches for process monitoring and control. Among the challenges in setting-up such systems is the difficulty of measuring the melt pool temperature as the major, microstructure-controlling process characteristic beyond initial composition. Even if it can be measured, the relationship between measured values and resulting quality of the built part are not straightforward. As a consequence, several different strategies for process monitoring and control are being pursued, including model-based as well as model-free approaches.

With developing maturity of the processes, the focus shifts from mastering the build process to improved control of its boundary conditions. For powder based processes, this includes powder characterization: Experience has shown that conventional test procedures may fail to capture important characteristics that influence processability. The variation of these from one material batch to another may thus go unnoticed unless evaluation procedures and standards are adapted $[12,13]$. Other aspects studied are e.g. the influence of the process atmosphere and the intensity distribution of the laser beam. 


\subsection{Materials}

Not surprisingly, there is a link between AM processes and materials: Stereolithography, for example, is essentially a polymer AM process, just like WAAM is clearly a metal AM process. However, a closer look will reveal that almost any AM process has by now been adapted to several material classes A typical approach is the use of filled polymers - in the case of FDM, for example, filaments can be based on materials similar to powder injection moulding feedstocks. Table 1 provides an overview of material-process already demonstrated.

Table 1. Overview of AM material group-process combinations, based on a collection by Lehmhus and Busse [14]. The list should be read with care, as new combinations are constantly emerging.

\begin{tabular}{|c|c|c|c|c|c|}
\hline \multirow[b]{2}{*}{$\begin{array}{l}\text { ASTM F2792 } \\
\text { process class }\end{array}$} & \multirow[b]{2}{*}{$\begin{array}{l}\text { Individual } \\
\text { process }\end{array}$} & \multicolumn{4}{|c|}{ Materials } \\
\hline & & $\begin{array}{l}\dot{\bar{\Xi}} \\
\stackrel{\Xi}{0} \\
\stackrel{0}{0}\end{array}$ & 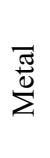 & 岂 & 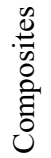 \\
\hline Binder jetting & 3D Printing & $\mathrm{X}$ & $\mathrm{X}$ & $\mathrm{X}$ & $\mathrm{X}$ \\
\hline \multirow{3}{*}{$\begin{array}{l}\text { Directed energy } \\
\text { deposition }\end{array}$} & Laser Engineered Net Shaping LENS $^{(\mathbb{R}}$ & - & $\mathrm{X}$ & $\mathrm{X}$ & $\mathrm{X}$ \\
\hline & Directed Light Fabrication DLF & - & $\mathrm{X}$ & - & - \\
\hline & Direct Metal Deposition DMD & - & $\mathrm{X}$ & - & - \\
\hline \multirow[t]{4}{*}{ Material extrusion } & Fused Deposition Modeling FDM & $\mathrm{X}$ & $\mathrm{X}$ & $\mathrm{X}$ & - \\
\hline & Multiphase Jet Solidification MJS & - & $\mathrm{X}$ & - & - \\
\hline & Robocasting & - & - & $\mathrm{X}$ & - \\
\hline & Freeze-form Extrusion Fabrication FEF & - & - & $\mathrm{X}$ & \\
\hline \multirow[t]{2}{*}{ Material jetting } & Multijet/PolyJet Modeling MJM/PJM & $\mathrm{X}$ & - & - & \\
\hline & Direct Printing DP & $\mathrm{X}$ & $\mathrm{X}$ & $\mathrm{X}$ & \\
\hline \multirow{4}{*}{$\begin{array}{l}\text { Powder bed } \\
\text { fusion }\end{array}$} & Laser Beam Melting LBM & - & $\mathrm{X}$ & - & $\mathrm{X}$ \\
\hline & Selective Laser Sintering SLS2 & $\mathrm{X}$ & $\mathrm{X}$ & $\mathrm{X}$ & $\mathrm{X}$ \\
\hline & Direct Metal Laser Sintering DMLS & - & $\mathrm{X}$ & - & $\mathrm{X}$ \\
\hline & Electron Beam AM EBAM & - & $\mathrm{X}$ & - & \\
\hline \multirow[t]{2}{*}{ Sheet lamination } & Laminated Object Manufacture LOM & $\mathrm{X}$ & $\mathrm{X}$ & $\mathrm{X}$ & - \\
\hline & Plate Diffusion Brazing PDB & - & $\mathrm{X}$ & - & - \\
\hline Vat photopolym. & Stereolithography & $\mathrm{X}$ & $\mathrm{X}$ & $\mathrm{X}$ & $\mathrm{X}$ \\
\hline
\end{tabular}

A critical issue in manufacturing specifically of metallic materials via AM techniques is the question of whether AM parts can compete, in terms of mechanical properties, with their counterparts stemming from conventional manufacturing processes like casting and forging. Comparisons of this kind have been undertaken by several authors. A broad overview of such studies has recently been published by Hitzler et al. for laser-based powder bed processes [15]. Results collected include data on density, hardness, Young's modulus and strength for Al-, Fe-, Ti-, Co- and Ni-based materials. To provide an idea of capabilities and potential of AM, table 2 lists property ranges for a number of common engineering materials [15].

Although a generalization is difficult, typically tensile strength values of AM-produced materials are as high as or even higher than those of conventionally produced ones, provided samples are defect-free. Fatigue properties, on the other hand, are typically worse 
for AM, even if surface are post-processed by machining. HIP densification often alleviates this disadvantage.

Table 2. Reported tensile strength ranges for several LBM-processed engineering alloys as collected by Hitzler et al. [15]. Processing conditions, secondary treatments except for heat treatments (all data for materials in non-heat treated states) etc. may differ. Besides, directionality of properties is not distinguished in our summary of Hitzler et al.'s results [15].

\begin{tabular}{|l|c|c|c|c|}
\hline Material & $\begin{array}{c}\text { Young's Modulus } \\
{[\mathrm{GPa}]}\end{array}$ & $\begin{array}{c}\text { Yield strength } \\
{[\mathrm{MPa}]}\end{array}$ & $\begin{array}{c}\text { Tensile strength } \\
{[\mathrm{MPa}]}\end{array}$ & $\begin{array}{c}\text { Elongation at } \\
\text { failure [\%] }\end{array}$ \\
\hline pure $\mathrm{Al}$ & - & $92-95$ & $106-111$ & $30-30.9$ \\
\hline A1Si10Mg & $62.6-77$ & $180-268$ & $250-436$ & $1.4-13$ \\
\hline A1Si12 & $55-76$ & $190-250$ & $300-368$ & $2-4.8$ \\
\hline pure Fe & $205.6-215.8$ & $246-305$ & $354-412$ & $>9.5$ \\
\hline 1.2344 & $188-194$ & $835-1236$ & $1150-1965$ & $1.5-4.1$ \\
\hline 1.4307 & - & $384-570$ & $549-717$ & $29.1-57.6$ \\
\hline pure Ti & $91-101$ & $518-533$ & $617-654$ & $5.1-17$ \\
\hline TiAl6V4 & $102-131.5$ & $770-1226$ & $920-1400$ & $0.4-8.4$ \\
\hline Inconel 718 & 204 & $889-907$ & $1137-1148$ & $19.2-25.9$ \\
\hline
\end{tabular}

The validation of AM processes for production of a growing number of established engineering materials has fuelled efforts to extend the scope of materials. This includes polymers, metals and ceramics as well as composites, as the latter term used here for uniform materials, excluding tailored composites, functionally graded materials (FGM) and multi-material solutions. Table 3 enumerates several examples of composite materials produced via AM processes.

Table 3. Examples of processes used for production of uniform composite materials. Related references include [14, 16-19].

\begin{tabular}{|l|c|c|c|}
\hline \multirow{2}{*}{ Process } & \multirow{2}{*}{ Matrix } & \multicolumn{2}{|c|}{ Reinforcement } \\
\cline { 3 - 4 } & 316L stainless steel & Material & Type \\
\hline Binder jetting & HDPE & cenospheres & particles \\
\hline FDM & $\begin{array}{c}\text { thermoplastics (PEEK, } \\
\text { PPS, ABS, etc.) }\end{array}$ & carbon, glass & $\begin{array}{c}\text { short to continuous } \\
\text { fibres }\end{array}$ \\
\hline FDM & thermoplastics & carbon/CNT & nanotubes \\
\hline FDM & polyamide & carbon, glass, aramide & continuous fibres \\
\hline FDM (FFF) & AlSi10Mg & TiC & particles \\
\hline LBM & titanium & TiC & particles \\
\hline LBM & titanium & carbon/CNT & nanotubes \\
\hline LBM (DMLS) & polyamide & glass, carbon & short fibres \\
\hline SLS & & & \\
\hline
\end{tabular}

\section{Future Trends in Additive Manufacturing}

\subsection{Advanced Alloys}

The increasing diversity of materials processed by means of AM techniques has already been discussed in the preceding section, in which, however, the focus was mainly on known compositions transferred from conventional to the large variety of AM manufacturing techniques. In recent years, considerable advances have been made regarding alloy 
development explicitly aimed at AM processes like powder-based LBM, exploiting the extreme inherent thermal conditions of the laser process, particularly rapid solidification of the melt pool, and control of the platform temperature for in-situ heat treatment. Besides novel steel grades [20], advanced aluminium alloys with enhanced properties (as e.g. proposed by Knoop et al. [21], see also Fig. 1) have been introduced.
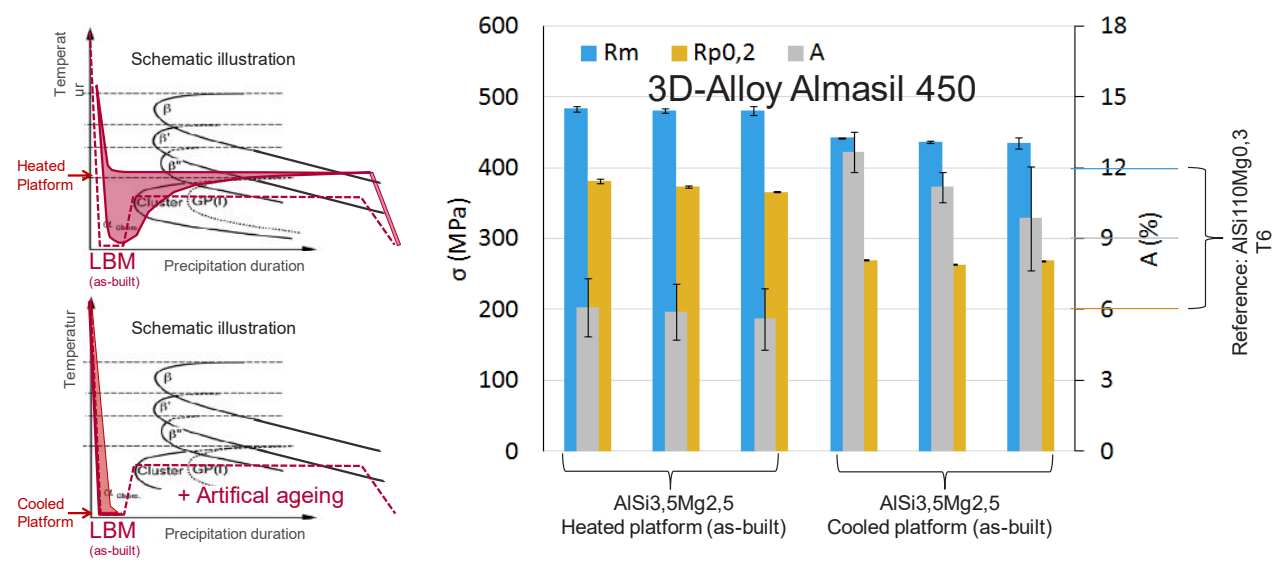

Fig. 1. Mechanical properties in as-built condition of a novel Al-Si-Mg alloy after rapid solidification to different platform temperatures: in-situ ageing during LBM with heated platform versus maintenance of oversaturated solution with cooled platform for subsequent artificial ageing [21].

\subsection{Multi-material Solutions: From Component to Material Level}

Because they deposit material not only layer-by-layer, but also line-by-line, most AM processes provide access to every single volume element, or voxel, which will later make up the material and the produced part. The size of these voxels is primarily controlled by the building resolution of the respective AM system. This possibility to modify a part's internal structure has fuelled massive interest in $\mathrm{AM}$ as the major tool for $3 \mathrm{D}$ materials science, i.e. the realization of tailored materials virtually developed using computational materials science techniques.

As backbone of such approaches, processes capable of managing several materials in a single build job are sought for. Powder bed processes like LBM face difficulties in this respect, though suggestions e. g. based on complete removal of one powder and application of another before resuming the build job have been discussed and realized on lab scale [2225]. More suited for production of multi-material parts are those processes that, instead of locally consolidating a material volume (powder bed processes, vat photopolymerization), locally supply material rather than energy, or both (directed energy deposition, material jetting, material extrusion). Several examples of multi-material FDM-systems exist. The PolyJet material jetting technology marketed by Stratasys offers a digital material technique in which final material components are mixed immediately prior to deposition, allowing the designer to work with smooth material transitions and property gradients. DED has been used multiple times in the past to produce parts with a (typically one-dimensional) concentration gradient. This can be used for situations in which dissimilar material joints with abrupt composition change are prone to failure [26,27], or as a tool for accelerated materials discovery [28].

An interesting alternative facilitating compositional and property changes and gradients is the binder jetting process, despite the fact that it is based on a powder bed approach. 
When applied to production of ceramic or metallic components, the polymeric binder injected into the powder bed is usually completely removed before sintering of the remaining ceramic of metal structure. However, the binder can also be used as a carrier medium for additives. Godlinski et al. have demonstrated this possibility in the past by creating a carbon gradient in a stainless steel component [29]. Systems working with multiple binders would thus offer complete spatial control of material modification at a typical resolution of approximately $200 \mu \mathrm{m}$.

Local modification of properties can also be achieved by modification of the local processing conditions instead of the chemical composition. This technique is typically applied to the beam-based processes LBM, EBM and DED. Here, laser or electron beam power, scan speed and hatch distance can be adjusted to ascertain that each voxel is subjected to an individual temperature-vs.-time (T-t) profile. In practice, degrees of freedom are limited by the necessity, among others, to achieve full density of the final part. Tailoring the T-t profile is complicated, because the thermal conduction towards the base plate as the dominant mode of beam heat removal, varies with part geometry and build height. Nevertheless, it has been shown that varying process parameters can locally vary the solidification mode (columnar/equiaxed) of Ni-base alloys and hence the grain morphology in the final part [30-32]. Additionally, the re-heating of voxels in layers below the topmost layer (where the laser beam is passing) constitutes an "intrinsic heat treatment" strong enough to trigger solid-state phase transformations [33, 34]. This way, e.g. precipitation strengthening can be induced during the DED build process, allowing in principle for locally varying hardness, e.g. hardened shell and soft core of a part.

Another way of varying local materials properties is by intentionally changing the porosity of the produced material. This occurs either by choosing parameters that lead to a certain porosity, or by producing structures that include voids in the input CAD file itself. By increasing porosity [35], material stiffness can be effectively lowered. These approaches are very similar in concept to the field of architectured materials and additively manufactured lattice structures.

A general issue raised by the introduction of multi-material manufacturing techniques is the aim of optimizing material distribution within a part to achieve highest levels of weightspecific performance. Whereas conventional topology or shape optimization usually assume homogeneous material properties, multi-phase topology optimization (MPTO) can tackle this problem: Introduced by Burblies [36], it is based on linear-elastic finite element analysis (FEA). In a first step, properties of two or more materials are arbitrarily associated with individual elements of the FE model. The volume fraction of each material is predefined and remains constant in the process. An initial calculation of the response to the dominant load case yields, total strain energy values for each element. Where these are high and the respective element has low stiffness, material associations are switched with a high stiffness element exhibiting low strain energy values. Subsequently, a further simulation run is executed, resulting in additional exchanges. The process is iteratively repeated until a pre-defined abort criterion is reached. The method is scalable from macroscopic problems [37] to the microscopic level.

\subsection{From Art to Smart Part: Sensor and Electronics Integration in AM}

Quite another kind of multi-material components are those that introduce functional capabilities through their hybrid build-up. Less complex examples include e.g. the integration of geometrically defined heat conduction paths in polymers, or electrical conductors. At the high complexity end of the spectrum, approaches of the latter kind can be further developed towards integration or even direct build-up of electronic components and systems $[14,38]$. 
The strategies adopted in integration of sensors and electronic systems differ widely. Categorization can be based on the localization of the systems in the final component. Surface integration is the most accessible approach in this respect and is occasionally been done using a secondary direct write (DW) process for functionalization: Meanwhile, the market also offers integrated AM systems which combine the volume build-up process, e.g. material jetting, with a direct write process like dispensing or inkjet printing in the same device. This allows interruption of the first process and addition of functional elements via the second before the first is resumed, burying the added sensors, interconnects etc. within the part. By this means, what is essentially surface integration becomes volume integration. Complexity increases if such functionalization can be sufficiently controlled to allow transgression of build planes. In principle, such techniques can be adapted e. g. to powder bed processes, too. Alternatively, by making use of process variants better suited to handling of multiple materials, a single technique could be used to build up a smart part directly, if the range of available materials extends from structural to functional (electrically conductive, capable of sensing, e. g. via piezoresistive effects, etc.). Studies along these lines are typically based on polymeric materials, for two reasons: On the one hand, a metallic base material requires additional solutions for electric insulation, besides typically affording significantly more severe processing conditions - on the other hand, the emergence of direct write technologies for printing of sensors has already provided a considerable number of materials that fulfil many requirements of either pure (polymer) AM systems, or of solutions integrating AM with DW approaches. As a consequence, integration of sensors and electronic systems in metal AM typically relies on separately built, encapsulated systems which are integrated into a component by placing them in a cavity within the part volume during an interruption of the build process, then continuing that process in order to fully enclose the electronic system. Examples of this kind have been reported for RFID, sensor and even sensor and actuator systems. Because non-AM/DW processes will usually yield higher performance sensor- and electronic systems (see comparisons of performance between printed/organic and conventional, silicon based electronics), this strategy can also be a reasonable choice for polymeric components. One of its drawbacks, however, especially in the case of sensing and actuation as tasks of the integrated system, is the difficulty of creating a strong and defined connection between sensor/actuator system and component. Fig. 2 provides an example of a polymeric screw produced via DLP incorporating piezoresistive strain sensors for torque monitoring: The latter have been produced in a separate setup using functional printing methods.

Table 4 below lists examples of process combinations which have already been used to create sensor-/electronics-integrated AM components. Localization of systems within the component is used as primary feature for categorization, while implementation of the manufacturing process serves as secondary criterion. The overview is based on a more detailed review of the topic by Lehmhus and Busse [14].

Besides generally supporting the concept of intelligent components, the combination of $\mathrm{AM}$ and sensor integration can also be employed to redefine conventional product development and optimization processes. A manufacturing concept taking up this very idea has been discussed by Lehmhus et al. [39]. In it, the general concept of cloud-based design and manufacturing is extended to include usage data collection, which is used to feed middle-of-life lifecycle data into the design process that generates the production data (CAD model etc.) for new product versions. In this theoretical concept, no single product equals the preceding one, as each one of them is based on an extended data base of usage information. To be economically viable, this approach requires an automated design process which can handle product adaptation autonomously. Beyond technical, this approach raises legal issues e.g. in terms of privacy, or w. r. t. product certification and homologation. 


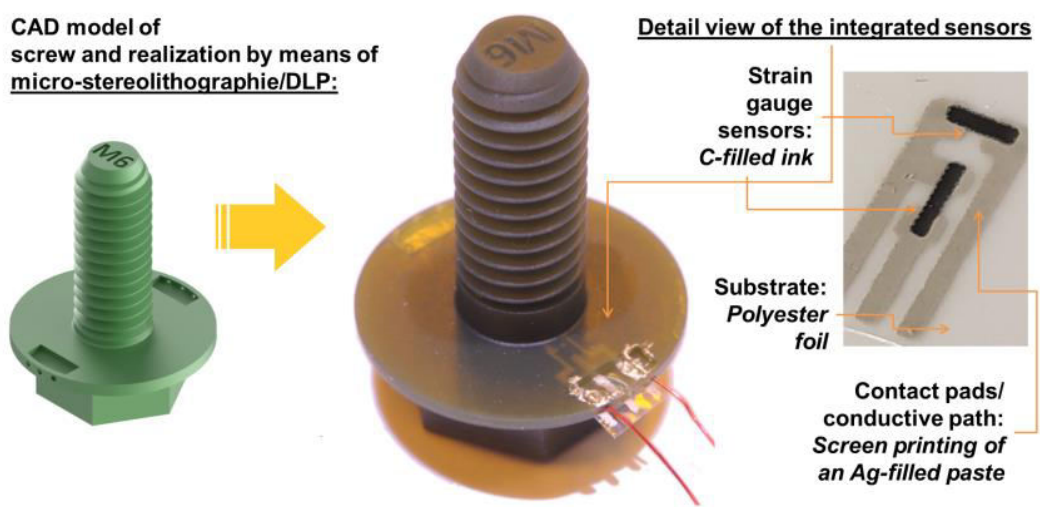

Fig. 2. Sensor and electronics integration in AM: Screw with integrated sensor (Image courtesy of IMSAS, University of Bremen, www.imsas.uni-bremen.de).

Table 4. Examples of process combinations yielding sensor-integrated AM parts as documented in the literature. Adapted from Lehmhus and Busse [14].

\begin{tabular}{|c|c|c|c|c|}
\hline \multicolumn{2}{|c|}{ Type of integration } & \multicolumn{3}{|c|}{ Sensor, actuator or electronic system vs. part production scenario } \\
\hline & & $\begin{array}{l}\text { Separate process, } \\
\text { separate manufacturing } \\
\text { system }\end{array}$ & $\begin{array}{l}\text { Separate process, } \\
\text { same (hybrid) } \\
\text { manufacturing system }\end{array}$ & $\begin{array}{l}\text { Same process, same } \\
\text { manufacturing system }\end{array}$ \\
\hline \multirow{2}{*}{ 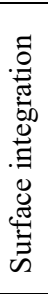 } & $\begin{array}{l}\text { planar } \\
\text { surfaces }\end{array}$ & $\begin{array}{l}\text { Inkjet printing, } \\
\text { electroless } \\
\text { Cu plating/3DP (binder } \\
\text { jetting) }\end{array}$ & & \\
\hline & $\begin{array}{l}\text { non-planar } \\
\text { surfaces }\end{array}$ & $\begin{array}{l}\text { Aerosol Jet } \\
\text { Aerosol Jet }^{\mathrm{TM}} / \mathrm{FDM} \\
\text { Dispensing/FDM } \\
\text { Aerosol Jet }^{\mathrm{TM}} / \mathrm{SLS}\end{array}$ & $\begin{array}{l}\text { Aerosol Jet }{ }^{\mathrm{TM}}, \\
\mu \text { Dispensing/FDM }\end{array}$ & \\
\hline \multirow{2}{*}{ 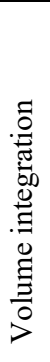 } & $\begin{array}{l}\text { on build } \\
\text { planes }\end{array}$ & $\begin{array}{l}\text { Fibre-optic sensor/UAM } \\
\text { Screen printing/UAM, } \\
\text { LOM } \\
\mu \text { Dispensing/DLP } \\
\text { Aerosol Jet }^{\mathrm{TM}} / \text { PolyJet }\end{array}$ & $\begin{array}{l}\text { Dispensing/Polyjet } \\
\text { Wire embedding, } \\
\text { Dispensing/FDM } \\
\text { Wire embedding/FDM } \\
\text { Dispensing/SLS }\end{array}$ & $\begin{array}{l}\text { Dispensing/Disp. } \\
\text { Inkjet printing/3DP } \\
\text { (binder jetting) }\end{array}$ \\
\hline & $\begin{array}{l}\text { crossing } \\
\text { build planes }\end{array}$ & $\begin{array}{l}\text { Dispensing/3DP (binder } \\
\text { jetting) } \\
\text { SMT devices/SLS } \\
\text { RFID system/LBM } \\
\text { piezoel. Actuator/LBM }\end{array}$ & $\begin{array}{l}\text { Dispensing/SLA } \\
\text { Dispensing/FDM } \\
\text { Dispensing/photo curing }\end{array}$ & $\begin{array}{l}\text { For polymers, DP and } \\
\text { dispensing, for metals, } \\
D E D \text { processes have } \\
\text { potential. }\end{array}$ \\
\hline
\end{tabular}

\section{Conclusion}

Additive Manufacturing is in an extremely dynamic phase of its technological development, gaining day by day both in width and depth within the already established areas while at the same time extending its scope towards new materials, new combinations of these, and new concepts in terms of processes, materials, equipment and usage concepts. The present paper has highlighted two of these trends, namely 
- the development of materials specifically tailored to achieve optimized properties under the boundary conditions of AM processes,

- the potential of AM techniques to realize complex multi-material parts at resolutions from the micro- to the macroscopic scale, and

- the possibility of further extending complexity, functionality and customization of AM parts by endowing them with the additional capabilities integrated electronic systems may provide - identification, sensing, actuation etc.

Common to these developments is that they have not yet or only just reached the commercial market. Despite this fact, AM as such is gaining and securing notable shares in several markets, based on the available technologies and materials. The message that this article may thus convey is that there is still a lot more to be expected from Additive Manufacturing, and that from today's perspective, its full potential remains a promising object of study and discovery.

The authors would like to express their gratitude towards Professor Spiros Pantelakis of the University of Patras for the opportunity to present our ideas and views as keynote at the ICEAF V conference.

\section{References}

1. T. Wohlers [Ed.]. Wohlers Report 2018. Fort Collins: Wohlers Associates; 2018.

2. B. P. Conner, G. P. Manogharan, A. N. Martof, L. M. Rodomsky, C. M. Rodomsky, D. C. Jordan, J. W. Limperos, Additive Manufacturing 1-4, 64 (2014)

3. D. Wu, D. W. Rosen, L. Wang, D. Schaefer, Computer-Aided Design 59, 1 (2015)

4. D. Lehmhus, A. von Hehl, K. Kayvantash, R. Gradinger, T. Becker, K. Schimanski, M. Avalle, Materials \& Design 66, 385 (2015)

5. A. Uriondo, M. Esperon-Miguez, S. Perinpanayagam, Journal of Aerospace Engineering 229, 2132 (2015)

6. M. Cronskär, M. Bäckström, L.-E. Rännar, Rapid Prototyping Journal 19, 365 (2013)

7. C.-Y. Liaw, M. Guvendiren, Biofabrication 9, 024102 (2017)

8. A. Youssef, S. J. Hollister, P. D. Dalton, Biofabrication 9, 012002 (2017)

9. F. Trevisan, F. Calignano, A. Aversa, G. Marchese, M. Lombardi, S. Biamino, D. Ugues, D. Manfredi, J. of Appl. Biomaterials \& Functional Materials 16, 57 (2018)

10. Active Standard ASTM F2792 Standard Terminology for Additive Manufacturing Technologies. West Conshohocken: ASTM Int.; 2012.

11. D. Ding, Z. Pan, D. Cuiuri, H. Li, Int. J. of Manufact. Techn. 81, 465 (2015)

12. F. Petzoldt, C. Aumund-Kopp, Standards for metal Additive Manufacturing: A global perspective, Metal Additive Manufacturing, Inovar Com. Ltd., Shrewsbury, UK, 2016, p. 45.

13. D. Lehmhus, C. Aumund-Kopp, M. Uhlirsch, L. Sentker, T. Haupt, A. Ditsche1, D. Zibelius, F. Petzoldt, M. Busse, Powder Metallurgy 61, invited for submission (2018)

14. D. Lehmhus, M. Busse, In: S. Bosse, D. Lehmhus, W. Lang, M. Busse, Materialintegrated Intelligent Systems, Wiley-VCH Verlag, Weinheim 2018, p. 217

15. L. Hitzler, M. Merkel, W. Hall, A. Öchsner, Adv. Eng. Mat. 20, 1700658 (2018)

16. A. K. Singh, B. Patil, N. Hoffmann et al., JOM 70, 303 (2018)

17. A. K. Singh, B. Patil, N. Hoffmann et al., JOM 70, 310 (2018) 
18. M. Yakout, M. A. Elbestawi, Proceedings of the 6th International Conference on Virtual Machining Process Technology (VMPT), Montréal, May 29th - June 2nd, 2017

19. K. Chang, D. Gu, Journal of Materials Research 31, 281 (2016)

20. J. Günther, F. Brenne, M. Droste, M. Wendler, O. Volkova, H. Biermann, T. Niendorf, Nature Scientific Reports 8, 1298 (2018), DOI: 10.1038/s41598-018-19376-0

21. D. Knoop, F. Mostaghimi, A. von Hehl, S. Jäger, B. Mais, DGM Fachtagung Werkstoffe und Additive Fertigung, April 25 $5^{\text {th }}-26^{\text {th }}, 2018$, Potsdam, Germany.

22. T. Laumer, M. Karg, M. Schmidt, Physics Procedia 39, 518 (2012)

23. Y. Chivel, Physics Procedia 83, 891 (2016)

24. A. G. Demir, B. Previtali, Manufacturing Letters 11, 8 (2017)

25. C. Wei, L. Li, X. Zhan, Y.-H. Chueh, CIRP Annals, in press, corrected proof, DOI: 10.1016/j.cirp.2018.04.096 (2018)

26. S. M. Thompson, L. Bian, N. Shamsaei, A. Yadollahi, Additive Manufacturing 8, 36 (2015)

27. B. E. Carroll, R. A. Otis, J. P. Borgoni, J.-O Suh, R. P. Dillon, A. A. Shapiro, D. C. Hofmann, Z.-K. Liu, A. M. Beese, Acta Materialia 108, 46 (2016)

28. H. Knoll, S. Ocylok, A. Weisheit, H. Springer, E. Jägle, D. Raabe, Steel Research International 87, 1 (2016)

29. D. Godlinski, S. Morvan, Materials Science Forum 492-493, 679 (2005)

30. H. Helmer, A. Bauereiß, R. F. Singer, C. Körner,. Mat. Sci. Eng. A 668, 180 (2016)

31. N. Raghavan, R. Dehoff, S. Pannala, S. Simunovic, M. Kirka, J. Turner, N. Carlson, .S. S. Babu, Acta Materialia 112, 303 (2016)

32. M. M. Kirka, P. Nandwana, Y. Lee, R. R. Dehoff, Scripta Materialia, 135, 130 (2017)

33. W. Xu, E. W. Lui, A. Pateras, M. Qian, M. Brandt, Acta Materialia, 125, 390 (2017)

34. P. Kürnsteiner, M. B. Wilms, A. Weisheit, P. Barriobero-Vila, E. A. Jägle, D. Raabe, Acta Materialie 129, 52 (2017)

35. S. J. Wolff, S. Lin, E. J. Faierson, W. K. Liu, G. J. Wagner, J. Cao, Acta Materialia 132, 106 (2017)

36. A. Burblies, M. Busse, Computer Based Porosity Design by Multi Phase Topology Optimization. Multiscale \& Functionally Graded Materials Conference (FGM2006), October $15^{\text {th }}-18^{\text {th }} 2006$, Honolulu (Hawaii), USA

37. D. Schittenhelm, A. Burblies, M. Busse, Forschung im Ingenieurwesen 82, 131 (2018)

38. D. Lehmhus, C. Aumund-Kopp, F. Petzoldt, D. Godlinski, A. Haberkorn, V. Zöllmer, M. Busse, Procedia Technology 26, 284 (2016)

39. D. Lehmhus, T. Wuest, S. Wellsandt, S. Bosse, T. Kaihara, K.-D. Thoben, M. Busse, Sensors 15, 32079 (2015) 